\title{
Translational Research in Medicine: Reverse the Process and Support it for Success
}

\author{
Hugo A Barrera-saldana \\ Universidad Autónoma de Nuevo Lleon. Instituto Tecnológico de Monterrey, México
}

Submission: April 8, 2017; Published: April 21, 2017

*Corresponding author: Hugo A Barrera Saldaña, PhD, Professor of Biochemistry and Molecular Medicine, School of Medicine and University Hospital at the Universidad Autónoma de Nuevo Lleon. Instituto Tecnológico de, Monterrey, Mexico, Email: habarrera@gmail.com

\section{Opinion}

Our Universities are among the few in Latin America that have a prestigious medical school and affiliated hospitals staffed by professors from our clinical faculties. This unique combination greatly benefits the training of our students since they gain a solid preparation in the basic sciences and a great deal of clinical experience.

While this model is wonderful for training medical students, it does not necessarily guarantee that the clinical practice at the University Hospital benefits from the latest findings of the basic science researchers at the Medical School. In fact, it may lead to a disconnection between the discovery of basic science information and its application to clinical care. While basic scientists are concerned with discovering cellular and molecular mechanisms of diseases, advances that may not find applicability in the short term, clinicians are seeking innovative, improved diagnoses and treatments that can prevent and treat their patients' diseases and relieve their suffering.

This dilemma has led to an increased emphasis on so-called Translational Research, which aims to 'translate' discoveries in medical school laboratories to the bedside at the University Hospital to improve patient care and public health measures to prevent disease. This approach is intended to lead to a forward translation of biomedical discoveries to clinical applications. However, in reality, it is difficult for clinical practitioners to understand the language and methods of basic scientists. This leads to a reticence on their part to engage in meaningful discussions with the basic researchers and vice versaconsequently the efficiency and effectiveness of this one-way, forward attempt to connect the Medical School to its University Hospital may be limited despite everyone's best intentions.

In fact, it is common to see the basic scientists struggling to find appropriate disease models to test their fundamental molecular and cellular hypotheses and to see clinicians, who find it difficult to understand and apply scientific evidence generated in the research laboratories, interested in conducting and utilizing basic research. This scientific evidence is generally not available to them to pursue their ideas of better diagnostic tools and treatment regimens. This dual challenge is exacerbated for basic scientists by the institutional and federal agencies that provide incentives (i.e., research funding) to pursue basic discoveries and reward findings that result in publications in top journals that favor basic mechanistic discoveries. Conversely, clinicians are increasingly urged to spend more time in operating rooms, medical clinics, and physician offices since their incentives are reimbursements from health insurance companies and fees paid to them directly from the patients' pockets. Additional factors that contribute to this inefficient and ineffective translational research are the common feelings of some basic scientists who feel that simply obtaining biopsies or fluids for ethical human subject research does not deserve co-authorship in publications that use patient materials and records. Scientist-clinician interactions are conversely complicated by some clinical practitioners believing that they "own" the patient materials and information and thus deserve authorship credit since the research would not have been possible without their patients' involvement. Therefore, bickering occurs and frequently leads to incompatible expectations and no new research findings or clinical applications result!.

After many years of facing this dilemma, acknowledging that there is some truth to the claims and concerns of both basic scientists and clinicians and their different incentives, I believe some best practices would improve basic-clinical collaborations which in turn would improve clinical outcomes and hence, provide incentives for institutions to supply needed resources. Also, I have arrived at the conclusion that we have to initially reverse the one-way direction traditionally used for translational research. In other words, instead of basic scientists investigating their own areas of interest without a clear sense of how their discoveries and inventions might lead to improved 
clinical outcomes, they should start by investigating what knowledge and tools clinicians need for their practice and public health prevention strategies. By the same token, clinicians need to overcome their fear of visiting the basic science departments so they can describe to their basic research counterparts their needs and ideas and how to meet them. This will require that both groups sit down and discuss the terms for collaborating, providing financial support for the research, and sharing credit for findings. It is always wise for the leaders of each side to agree beforehand on authorship of any publication or benefit that derives from their collaboration, since it is far easier to negotiate such issues in a collegial fashion before fame or fortune arrives. Good research that improves health will always have plenty of credit to be shared by all those who contribute to successful investigations that lead to improved applications [1-7].

By having the clinician explain to the basic scientist what the biggest challenges faced at the bedside are and offering to collect biopsies, fluids, and relevant data from their patients, the sense of translational research becomes reversed and more effective. This does not mean that the current translational approach is not important, but rather that starting at the bedside and reverse designing good basic experiments is also valuable and the combination of the two approaches will lead to discoveries that improve therapies and preventive strategies. In this reversing, any project at the Medical School will have as its objective to discover knowledge explicitly intended to enhance clinical practice and public health. This becomes a win-win situation for all the stakeholders: science at the school continues to grow not only through patents (which can provide financial support) and publications (which lead to more grants), but also medicine at the hospital improves through enhanced innovative care which better serves the population-i.e, the outcome that should be the primary goal for everyone, including the institutions. However, in order to make the process of reverse translational research in medicine more effective and efficient than only using a forward- looking translational approach, institutional support is necessary. From over three decades of experience I have identified the following valuable best Practices:

1. Joint seminars, where basic and clinical faculties can discuss and forge alliances.

2. Early participation of undergraduate students in research projects.

3. Supervisory committees for graduate students that contain clinicians as well as basic scientists.

4. Biobanks where biopsies from the hospital become science research specimens, after appropriate amounts are retained for clinical follow-up, re-diagnosis, or legal needs.

5. Databases containing relevant information of biobank materials (e.g., genetic data, patient outcomes, etc.)

6. Core laboratories operated by experts who take the time to explain the relevant technology and potential uses to their clinician colleagues.

7. Training in experimental design and analysis for young clinical scientists.

8. Training, guides, and professional aid (e.g., statistical analyses) for grant and manuscript preparation and submission for both basic scientists and clinicians and institutional support for these.

9. Assistance to identify opportunities to participate in international collaborations.

10. Communication with public and private funding agencies, pharma and biotech industries, to support translational and reverse translational science.

The benefits of implementing support and reversing the sense of translational research in medicine would be many. They range from increasing prestige for the institution, to more efficiently executing theses and projects and thus increasing research productivity; better training of students and continuous enhancement of the careers of both basic science and clinical faculty; improving the impact in health indicators, to better governmental and societal recognition. Collectively, these would result in increased funding for research making contract research and clinical trials more attractive for the pharma and biotech industry, and to expand our overall sources of funding to sustain the growth of our research enterprise.

Finally, and very important, this dualist approach would result in a virtuous and autocatalytic circle to enhance institutional value for the faculty as well as partnerships and well-being of both individuals and the institution. Faculty deserve and expect a fair salary and recognition for their contributions, but after this the key to unleash the tremendous potential that reverse translational research can offer for unique institutions is acceptance of this approach as well as traditional translational research. As scientists and clinicians, we are fortunate to have the noble duty of carrying out research for acquiring the scientific knowledge needed to offer better care to our patients and preventive strategies for the public -this will allow us to declare, "mission accomplished!"

\section{Acknowledgement}

The author thanks George Stancel, Ph D and Sergio Lozano M D, for critical reading of the manuscript.

\section{References}

1. González-Rodríguez E, Jaramillo-Rangel G, Barrera-Saldaña HA (1997) Molecular diagnosis of deletions in the human multigene complex of growth and placental lactogen hormones. Am J Med Genet 72(4): 399402.

2. Garza-Rodríguez ML, Pérez-Maya AA, Monsivais-Ovalle DE, VelázquezVadillo JF, Barrera-Saldaña HA (2016) Institutional Biobank as a pillar of medical science. Salud Publica Mex 58(4): 483-489.

3. Mar-Aguilar F, Gómez-Almaguer D, Carrizales-Villareal JA, ViaderSalvadó JM, Barrera-Saldaña HA (1998) Detecting residual bcr-abl transcripts in chronic myeloid leukaemia patients using coupled 
reverse transcriptase-polymerase chain reaction with rTth DNA polymerase. Clin Lab Haematol 20(4): 221-224.

4. León-Cachón RB, Ascacio-Martínez JA, Gamino-Peña ME, Cerda-Flores RM, Barrera-Saldaña HA, et al. (2016) A pharmacogenetic pilot study reveals MTHFR, DRD3, and MDR1 polymorphisms as biomarker candidates for slow atorvastatin metabolizers. BMC Cancer 16: 74-84.

5. Delgado-Enciso I, Cervantes-García D, Martínez-Dávila IA, Ortiz-López R, Alemany-Bonastre R, et al. (2007) A potent replicative delta-24 adenoviral vector driven by the promoter of human papillomavirus 16 that is highly selective for associated neoplasms. J Gene Med 9(10): 852-861.

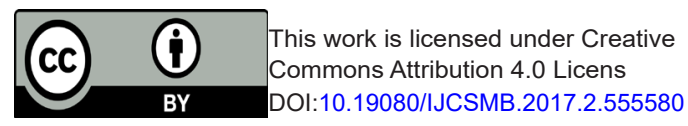

6. Rojas-Martínez A, Manzanera AG, Sukin SW, Esteban-María J, GonzálezGuerrero JF, et al. (2013) Intraprostatic distribution and long-term follow-up after AdV-tk immunotherapy as neoadjuvant to surgery in patients with prostate cancer. Cancer Gene Ther 20(11): 642-649.

7. Alcazar-González GA, Calderón-Garcidueñas AL, Garza-Rodr guez ML, Rubio-Hernández G, Escorza-Treviño S, et al. (2013) Comparative study of polymorphism frequencies of the CYP2D6, CYP3A5, CYP2C8 and IL-10 genes in Mexican and Spanish women with breast cancer. Pharmacogenomics 14(13): 1583-1592.

\section{Your next submission with Juniper Publishers will reach you the below assets}

- Quality Editorial service

- Swift Peer Review

- Reprints availability

- E-prints Service

- Manuscript Podcast for convenient understanding

- Global attainment for your research

- Manuscript accessibility in different formats ( Pdf, E-pub, Full Text, Audio)

- Unceasing customer service

Track the below URL for one-step submission https://juniperpublishers.com/online-submission.php 